\title{
PHYTOSYNTHESIS OF SILVER NANOPARTICLES USING HYGROPHILA AURICULATA LEAF EXTRACT AND ASSESSMENT OF THEIR ANTIBACTERIAL AND ANTIOXIDANT PROPERTIES
}

\author{
BHARATHI S. ${ }^{1}$, S. KUMARAN ${ }^{2}$, G. SURESH ${ }^{2}$, B. RAMESH ${ }^{3}$, M. S. NALINA SUNDARI ${ }^{*}$
}

1Department of Zoology, Queen Mary's College, Chennai 600004, Tamil Nadu, ${ }^{2}$ Department of Microbiology, Sri Sankara Arts and Science College, Kanchipuram 631561, Tamil Nadu, ${ }^{2}$ Department of Biotechnology, Sri Sankara Arts and Science College, Kanchipuram 631561, Tamil Nadu Email: drnalinas@yahoo.in

Received: 17 Jul 2018, Revised and Accepted: 04 Sep 2018

\section{ABSTRACT}

Objective: In this study, the phytosynthesis of silver nanoparticles (AgNPs) using leaf extracts of Hygrophila auriculata (HA) and their biological activities was investigated.

Methods: The synthesis of AgNPs was done by using the green synthetic method and analyzed by UV-Visible spectroscopy, X-ray diffraction (XRD), fourier transform infrared spectroscopy (FTIR) and further characterized by transmission electron microscopy (TEM) and dynamic light scattering (DLS). The antibacterial activity of HA AgNPs was studied by agar well diffusion method and micro broth dilution method for determination of minimum inhibitory concentration (MIC). The antioxidant potentials of HA AgNPs were detected by Diphenyl-1-picryl hydrazyl radical scavenging assay (DPPH), Phosphomolybdenum assay, reducing power assay.

Results: The prepared HA AgNPs showed characteristic absorption peak at $420 \mathrm{~nm}$ in the UV-Vis spectrum. FTIR spectra had shown that the biomolecules present in leaf extract were responsible for the reduction and capping material of silver nanoparticles. XRD study showed the particles found to be crystalline in nature, with a face-centered cubic (fcc) structure. TEM and DLS results revealed that the AgNPs were mostly spherical with an average size ranging from $\sim 15-115 \mathrm{~nm}$ with a mean diameter of $40.96 \mathrm{~nm}$. The HA AgNPs showed good antibacterial activity and MIC against Staphylococcus aureus (ATCC 6538), Bacillus cereus (NCIM 2106), Pseudomonas aeruginosa (ATCC 9027) and Escherichia coli (ATCC 8739). In agar well diffusion method, the maximum zone of inhibition was found against Pseudomonas aeruginosa (ATCC 9027) with 18 mm and minimum zone of inhibition was found to be against Escherichia coli (ATCC 8739) with $13 \mathrm{~mm}$. The MIC of the HA AgNp was found to be $5 \mu \mathrm{g}$ against all the test organisms. In addition, the Diphenyl-1-picryl hydrazyl radical scavenging assay (DPPH), Phosphomolybdenum assay, reducing power assay revealed they can be used as the potential scavenger against deleterious damages caused by the free radicals.

Conclusion: The present study explored that Hygrophila auriculata which are efficient producers of AgNPs and could act as safe and cost-effective with potential antibacterial and antioxidant activities. These findings encourage studying HA AgNP further for their potential biological applications.

Keywords: Phytosynthesis, Hygrophila auriculata, Silver nanoparticles, Antibacterial, Antioxidant

(C) 2018 The Authors. Published by Innovare Academic Sciences Pvt Ltd. This is an open access article under the CC BY license (http://creativecommons.org/licenses/by/4.0/) DOI: http://dx.doi.org/10.22159/ijap.2018v10i6.28605

\section{INTRODUCTION}

The exploitation of inert metals like silver, gold, and platinum for synthesizing of nanoparticles and best use in various biomedical applications has been the current field of research in nanomedicine. The surface Plasmon resonance (SPR) of silver nanoparticles can be easily observed UV-Vis spectrophotometer has gained much attention than the other nanoparticles [1]. The use of environmentally benign materials like plants, bacteria, and fungi for the synthesis of AgNPs has been the emerging branch of nanotechnology. The eco-friendly and compatible nature of the green synthesized make use of them in pharmaceutical and biomedical application [2]. The ineffectiveness of synthetic antibiotics against drug-resistant bacteria has led to the reemergence of interest in silver, which has an ancient history as an antibacterial agent [3]. The broad spectrum antibacterial potential of AgNPs can be used against antibiotic-resistant bacteria including both gram-positive and gram-negative bacteria. The broad spectrum activity of AgNPs may be due to the small size that effectively penetrates and accumulates in the cell membrane of bacteria that cause disruption and loss of cell integrity [4]. A new opportunity has been introduced for the medical treatment with the development of nanoparticles as therapeutic agents. Plants provide natural capping agent and free from toxic chemical makes them suitable for silver nanoparticles synthesis. The green synthesis of AgNPs reported using various plant extracts including those from Eleutherococcus senticosus [5], Allium cepa [6], Artemisia marschalliana [7], Pedalium murex [8], Chenopodium murale [9], Delphinium denudatum [2].

In the present study, the aqueous leaf extract of Hygrophila auriculata was used for the rapid synthesis of AgNps which is simple, cost-effective and viable. The Hygrophila auriculata belong to the family Acanthaceae. The Ayurvedic system of medicine classifies as Seethaveryam, Mathuravipaka. The plant extract of Hygrophila auriculata shown to have hepatoprotective activity, antitumor activity, hypoglycemic activity, antioxidant activity, free radical scavenging activity, antibacterial activity, anthelmintic activity, haematinic effect, diuretic activity, anti-nociceptive activity, anti-inflammatory and antipyretic activity etc [10-13]. However, the metal reducing property of Hygrophila auriculata and their antibacterial and antioxidant activity are not well known. Hence, the present study is designed to synthesize silver nanoparticles using the aqueous extract of $H$. auriculata, characterization of synthesized nanoparticles and to investigate the possible antibacterial and antioxidant activities.

\section{MATERIALS AND METHODS}

\section{Materials}

\section{Collection of plant material}

The healthy plant of Hygrophila auriculata was collected from Vandavasi village, Tamil Nadu, India. The collected plant was identified at National Institute of Science Communication and Information Resources (NISCAIR), New Delhi The leaves of Hygrophila auriculata were washed with sterile distilled water to remove the surface contamination and were shade dried for three days at room temperature.

\section{Preparation of plant extract}

The air-dried leaves were powdered by using a blender. $10 \mathrm{~g}$ of plant powder was mixed with $100 \mathrm{ml}$ of sterile distilled water and kept in 
a water bath at $60{ }^{\circ} \mathrm{C}$ for $30 \mathrm{~min}$. The slurry was cooled to room temperature and then filtered by Whatman filter paper No. 1 . The filtered extract was refrigerated at $4{ }^{\circ} \mathrm{C}$ for further studies.

\section{Phytosynthesis of silver nanoparticles}

For the phytosynthesis of silver nanoparticles, $1.5 \mathrm{ml}$ of plant extract was mixed with $30 \mathrm{ml}$ of $1 \mathrm{mmol}$ aqueous silver nitrate solution and incubated at room temperature in dark condition. The mixture was kept undisturbed until the colorless solution turned dark brown revealing the synthesis of silver nanoparticles. The AgNPs obtained from the solution were then separated by repeated centrifugation at $10,000 \mathrm{rpm}$ for $20 \mathrm{~min}$ followed by dispersion of the pellet in sterile distilled water three times to remove the water-soluble biomolecules such as proteins and secondary metabolites. Then the water suspended nanoparticles were dried at $40{ }^{\circ} \mathrm{C}$ for $2 \mathrm{~h}$ and used for characterization.

\section{Characterization of phytosynthesized silver nanoparticles}

Formation of AgNPs was confirmed by Ultraviolet-visible spectral analysis. The absorbance spectra were recorded using Ultravioletvisible spectroscopy (Cecil UV-Visible Spectrophotometer CE7200) at a wavelength of 300-700 nm. FTIR Spectrometer was performed for the leaf extract and the synthesized silver nanoparticles with Perkin-Elmer Spectrum one FTIR 4200 spectrophotometer by KBr pellet method in the range of 4000-450 cm-1. The crystalline structures of the synthesized AgNPs were investigated by X-ray diffraction (XRD). Powdered samples were used for XRD, and the diffraction patterns were recorded in the scanning mode on Rigaku Mini Sludge 600 operated at $40 \mathrm{kV}$ with a current of $30 \mathrm{~mA}$ and $\mathrm{Cu} / \mathrm{K} \alpha$ radiation in $\theta-2 \theta$ configurations. The average particle size of the synthesized AgNPs was calculated using the Debye-Scherrer equation. The surface morphology of the AgNPs was examined using TEM. The particle size distribution was determined using the principle of dynamic light scattering technique made in Malvern Instruments at $25^{\circ} \mathrm{C}$ with 90 detection angle.

\section{Antibacterial screening}

The synthesized AgNPs obtained was tested for its antibacterial potential against Gram-positive bacteria, such as Staphylococcus aureus (ATCC 6538), Bacillus cereus (NCIM 2106), Pseudomonas aeruginosa (ATCC 9027) and Escherichia coli (ATCC 8739) that were archived from culture collection and maintained in Sri Sankara Arts and Science College, Department of Microbiology Laboratory. The strains were maintained on nutrient agar slants at $4{ }^{\circ} \mathrm{C}$. For agar well diffusion method, the agar plates were seeded with freshly prepared different pathogens. The cultures were diluted with fresh MHB to achieve OD corresponding to 0.5 (i.e., $10^{5}$ to $10^{6} \mathrm{CFU} / \mathrm{ml}$ using Mac Farland's standard). Agar wells with a diameter of $6 \mathrm{~mm}$ were made with the help of a sterile stainless steel cork borer. AgNPs of various concentrations such as $100,200,300 \mu \mathrm{g} /$ well were added for determining antibacterial activity. Sterile $1 \mathrm{mmol}$ silver nitrate $\left(\mathrm{AgNO}_{3}\right)$ solution was used as blank exhibited no activity against any of the used organisms. Amoxycillin $(10 \mu \mathrm{g})$ was used as a standard drug (CLSI, 2005). The plates were incubated at $37^{\circ} \mathrm{C}$ for $24 \mathrm{~h}$, and the zone of inhibition (ZOI; $\mathrm{mm}$ ) appearing around the wells was recorded [14].

\section{Minimum inhibitory concentration (MIC)}

MIC of AgNPs dispersions against bacteria was determined using microtiter broth dilution method according to the guidelines of the Clinical and Laboratory Standards Institute. $100 \mu \mathrm{L}$ of AgNPs was added to Mueller-Hinton broth into wells of the microtiter plate. To that bacterial suspensions (5 $\mu \mathrm{l}$ of $\left.10^{6} \mathrm{CFU} / \mathrm{ml}\right)$ were added. Each batch included a growth control well (no antimicrobial agent) and a negative control well (un-inoculated). Plates were incubated at $37^{\circ} \mathrm{C}$ for $24 \mathrm{~h}$ and evaluated for the MIC based on growth observed in the lowest dilution of the well after streaking on MHA plates [2].

\section{In vitro antioxidant assays}

\section{Diphenyl-1-picrylhydrazyl (DPPH) radical scavenging assay}

The free-radical scavenging activity of AgNPs was quantitatively studied using 2,2\'-diphenyl-1-picrylhydrazyl (DPPH) assay. Briefly, different concentrations $(100,200,300,400,500 \mu \mathrm{g} / \mathrm{ml})$ of AgNPs and ascorbic acid (positive control) were taken separately and mixed with $3 \mathrm{ml}$ of a methanolic solution of DPPH (final concentration 0.1 $\mathrm{mmol}$ ). The reaction mixture was shaken and kept for $\sim 30 \mathrm{~min}$ at room temperature in the dark. Thereafter, the reduction of the DPPH radical was calculated by using a UV-visible spectrophotometer (Cecil UV-Visible Spectrophotometer CE7200) at $517 \mathrm{~nm}$. The methanolic solution of DPPH without the sample served as a control [5]. The percentage inhibition was measured according to the following formula.

$$
\text { Percentage of inhibition } \%=\frac{\text { Absorbance of control }- \text { Absorbance of test }}{\text { Absorbance of control }} \times 100
$$

\section{Phospho molybdenum assay}

Phospho molybdenum method was used to estimate the total antioxidant capacity of HA AgNPs. About $0.1 \mathrm{ml}$ of five different concentrations of HA AgNPs $(100,250,500,750,1000 \mu \mathrm{l})$ were incubated in water bath at $95{ }^{\circ} \mathrm{C}$ for 90 min with $1 \mathrm{ml}$ of reagent solution (containing $0.6 \mathrm{M}$ sulphuric acid, $28 \mathrm{mmol}$ sodium phosphate, $4 \mathrm{mmol}$ ammonium molybdate in 1:1:1 ratio). After incubation, the tubes were cooled at room temperature. The reduction of molybdate by nanoparticles occurs and it was measured at $695 \mathrm{~nm}$ in UV-Vis Spectrophotometer. Ascorbic acid was used as standard and methanol used as blank [15].

\section{Reducing power assay}

Iron-reducing ability of the nanoparticles was determined by reducing power assay. Five different concentrations of HA AgNPs $(100,250,500,750,1000 \mu \mathrm{l})$ were separately mixed with $2.5 \mathrm{ml}$ of phosphate buffer $(0.2 \mathrm{M}, \mathrm{pH}-6.6)$ and $2.5 \mathrm{ml}$ of $1 \%$ potassium ferricyanide. Then, the mixture was incubated at $50{ }^{\circ} \mathrm{C}$ for $20 \mathrm{~min}$. To this, $2.5 \mathrm{ml}$ of trichloroacetic acid (10\%) was added and centrifuged at $3000 \mathrm{rpm}$ for $10 \mathrm{~min}$. From that, $2.5 \mathrm{ml}$ of supernatant was taken and mixed with $2.5 \mathrm{ml}$ of distilled water and $0.5 \mathrm{ml}$ of $\mathrm{FeCl}_{3}(0.01 \%)$. Green color complex was formed and the absorbance was measured at $700 \mathrm{~nm}$ in UV-Vis Spectrophotometer. Ascorbic acid was used as standard and phosphate buffer as blank. An increase in the absorbance of the reaction mixture indicated stronger reducing power [16].

\section{RESULTS AND DISCUSSION}

The aim of the study is the environmentally friendly synthesis of AgNP using plant extract and exploitation for biological activities. There are various reports on the use of the aqueous extract of the plant for synthesis of AgNp and applications as therapeutic drugs [17]. In the present study, AgNPs was synthesized using an aqueous extract of Hygrophila auriculata which acted as a reducing agent. The change of color of the silver nitrate to dark brown confirms the reduction of silver ions to AgNps (fig. 1).

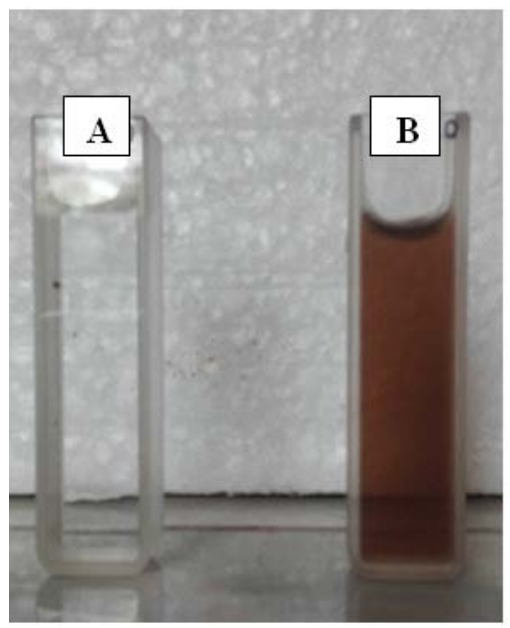

Fig. 1: Colorless to brown color indicating the synthesis of AgNP A. Control before synthesis B. Test after synthesis 
This was further confirmed by analysis on UV-spec that showed a sharp band at $420 \mathrm{~nm}$ which was specific for surface plasmon resonance (SPR) of silver nanoparticles (fig. 2).

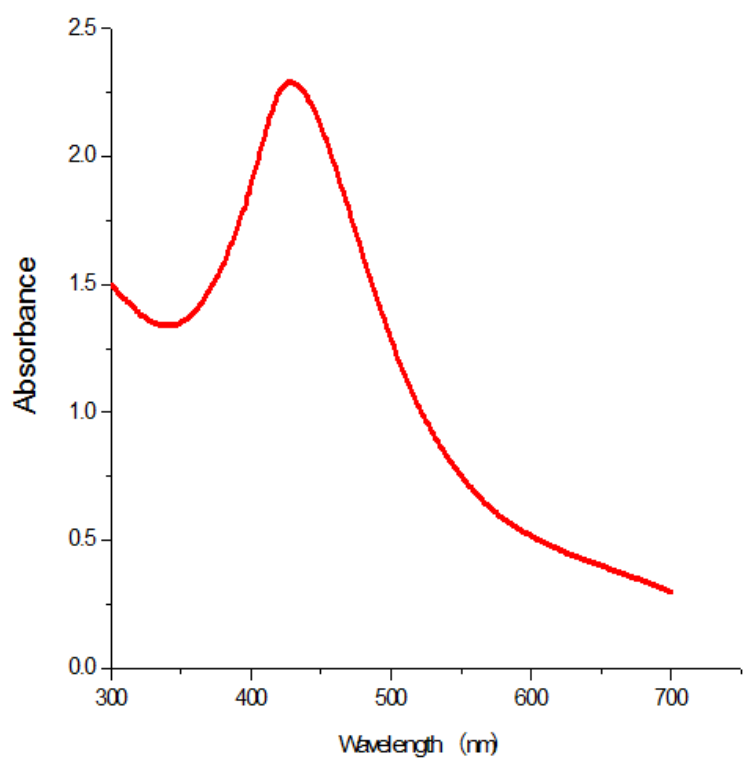

Fig. 2: UV-Vis spectral analysis of AgNPs biosynthesized using Hygrophilia auriculata leaf extract
The spherical nanoparticles will correspond to a single SPR band whereas the anisotropic molecules resemble two or more SPR peaks $[18,19]$. A single SPR peak was obtained in the present study reveals the spherical shape of the HA AgNPs. Further, the biosynthesized product was silver only as there were no additional peaks found in the spectrum. The increase in reaction time and concentration of AgNp increase the intensity of SPR peaks. Abbai et al., [5] reported 1 mmol of $\mathrm{AgNO}_{3}$ was completely reduced silver nanoparticles upon incubation at $80^{\circ} \mathrm{C}$ for $1.5 \mathrm{~h}$, which was indicated by the change in color of the reaction mixture from light yellow to dark brown. Interestingly, in our study, it took only $45 \mathrm{~min}$ for the reduction of 1 mmol of $\mathrm{AgNo}_{3}$ at room temperature this show that aqueous extract of Hygrophila auriculata has compounds that play important role in the bioreduction of silver salts.

\section{Fourier transform infrared spectroscopy (FTIR)}

FTIR spectra were recorded for HA plant extract and synthesized AgNP to identify the possible functional group present on AgNP (fig. 3). The absorption peak of HA plant extracts was at 670, 940, 1063, $1225,1431,1646,2133$ and $3261 \mathrm{~cm}-1$. The FTIR spectrum of the mixture containing HA plant extract and AgNP showed an intense peak at $1047,1435,1637,2002,2335,2926$ and 3437 . The peaks at 3437 and $3261 \mathrm{~cm}-1$ may correspond to primary and secondary amines. The peaks at 2926 and 2335, $2133 \mathrm{~cm}-1$ are characteristic of stretching vibrations of methyl groups or $\mathrm{C}-\mathrm{H}$ of aldehydic amine groups. The peaks at $1637,1646 \mathrm{~cm}-1$ due stretching vibrations of $\mathrm{C}=\mathrm{O}$ and $\mathrm{C}-\mathrm{N}$ group [20]. The peaks at 1431 and $1435 \mathrm{~cm}-1$ correspond to $\mathrm{O}-\mathrm{H}$ bending of carboxylic acid. The observance of peaks at 1063 and 1047 $\mathrm{cm}-1$ characteristic to glycoside (C-O-C) groups. The bioreduction of Ag+to AgNPs might be due to the presence of flavonoids, terpenoids, polyphenols, proteins present in the plant extracts [14].
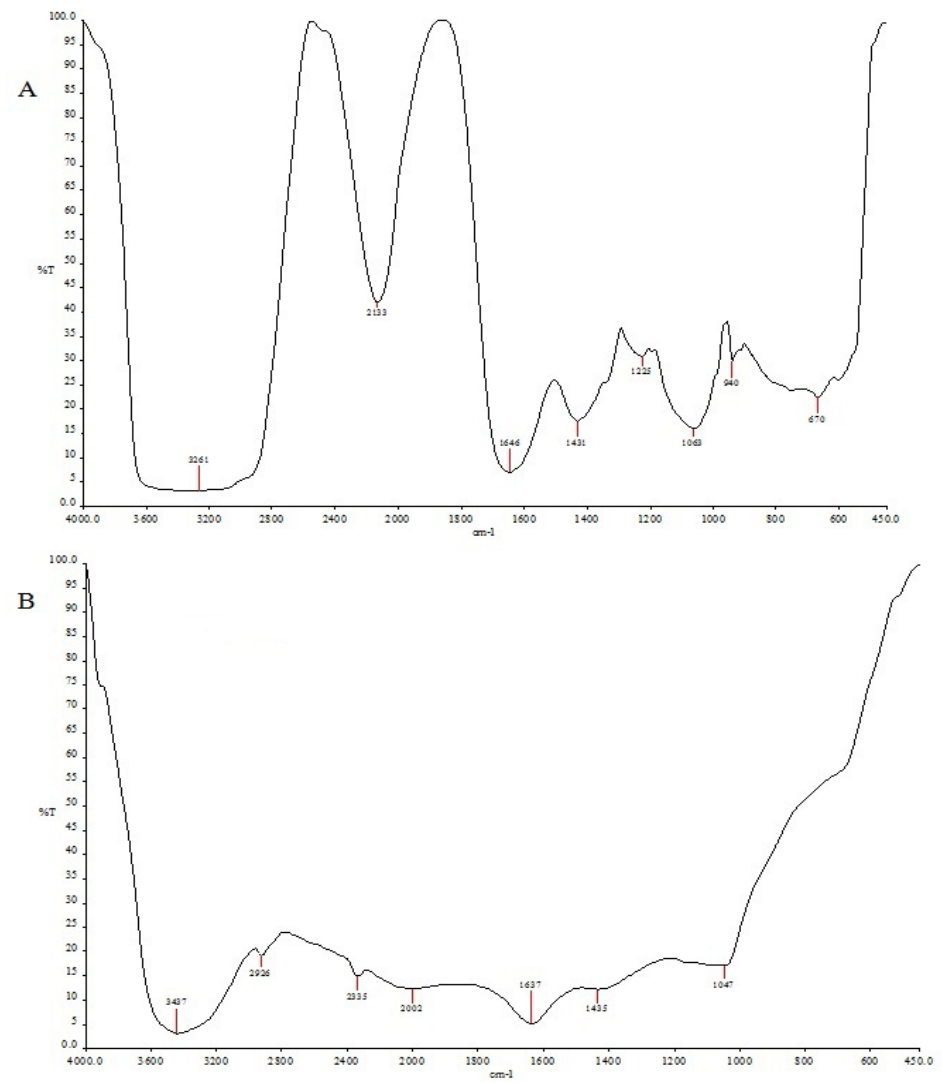

Fig. 3: The FTIR spectra of the Hygrophila auriculata aqueous leaf extract (A) and HAAgNPs (B)

\section{X-ray diffraction (XRD)}

XRD pattern showed four diffraction peaks at $32.09^{\circ}, 37.87^{\circ}, 43.99$ $\circ, 76.65^{\circ}$ attributed to (101), (111), (200), (311) lattice planes of the face-centered cubic crystalline silver respectively (fig. 4). These diffraction peaks were compared with the standard powder diffraction card of JCPDS files number 01-1167. The additional peaks such as $27.919^{\circ}, 32.09^{\circ}, 45.955^{\circ}, 54.06^{\circ}, 57.25^{\circ}$, and $67.06^{\circ}$ may 
indicate the presence of various phytochemicals on the surface of AgNps for their capping. The average size of the AgNp calculated using Debye-Scherer equation by determining the full length at a half maximum of the Bragg's reflection corresponding to (111) crystalline of AgNps. The average size was found to be $2.51 \mathrm{~nm}$.

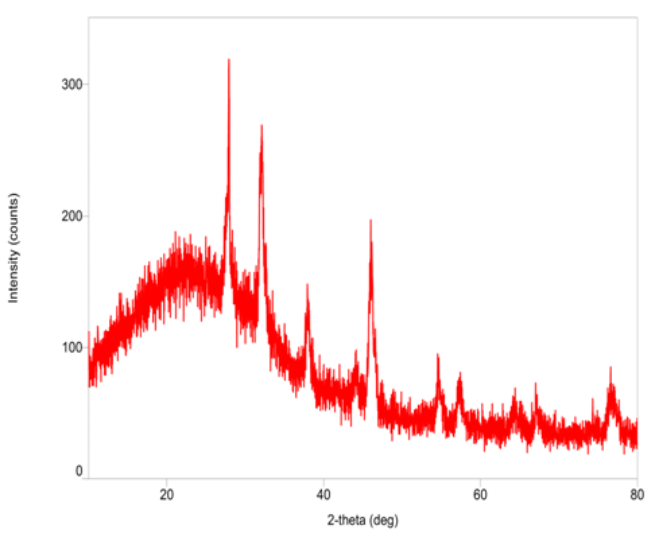

Fig. 4: XRD pattern of HA AgNp

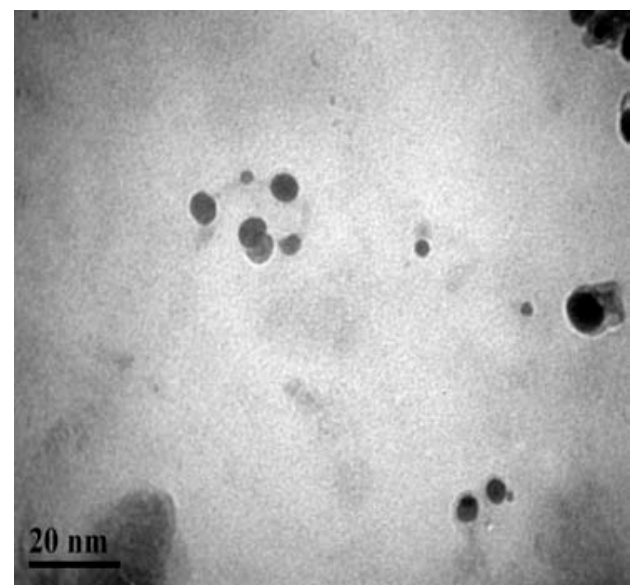

Fig. 5: TEM image of HA AgNp
Transmission electron microscopy (TEM) and dynamic light scattering (DLS)

The TEM analysis provided insight into the morphology and size details of the AgNps. The fig. clearly stated that the AgNps were spherical in shape (fig. 5). The particle size histogram shows that the synthesized AgNps size ranges from $\sim 15-115 \mathrm{~nm}$ with a mean diameter of $40.96 \mathrm{~nm}$.

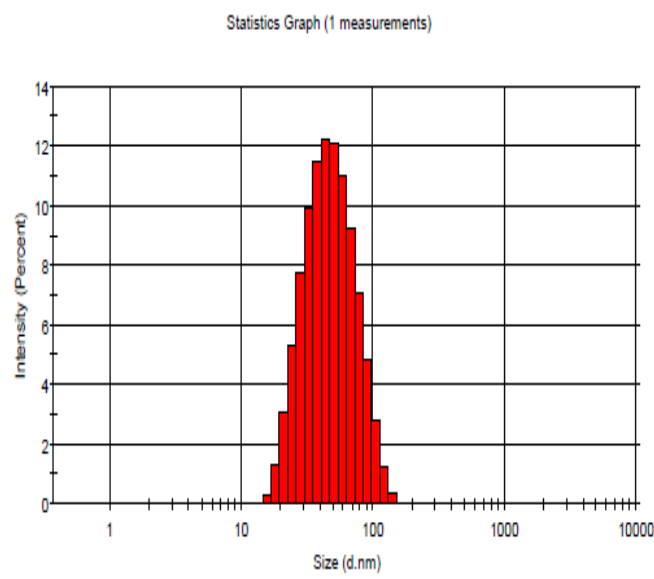

Fig. 6: Dynamic light scattering (DLS) of HA AgNp

\section{Antibacterial activity}

The antibacterial activity of synthesized AgNps was evaluated against such as Staphylococcus aureus (ATCC 6538), Bacillus cereus (NCIM 2106), Pseudomonas aeruginosa (ATCC 9027), Escherichia coli (ATCC 8739), by Kirby disc diffusion method using different concentration of AgNP $(100,200,300 \mu \mathrm{g} / \mathrm{ml})$ and with standard antibiotic amoxicillin. The result clearly states the HA AgNps have strong antibacterial activity against gram positive and gram negative bacteria with Zone of inhibition of $16 \mathrm{~mm}$ against Bacillus cereus and $18 \mathrm{~mm}$ against Pseudomonas aeroginosa (table 1). It is evidenced that the zone of inhibition increases with the increasing concentration of AgNps. The MIC values of HA AgNps against these test strains were determined by micro broth dilution method (table 2) and the result of MIC was compared with agar well diffusion method and found to be almost similar.

Table 1: Antibacterial activity of HA AgNp by agar well diffusion method

\begin{tabular}{|c|c|c|c|c|c|}
\hline \multirow{2}{*}{ Test strains } & \multirow{2}{*}{$\begin{array}{l}\text { Amoxycillin } \\
\text { (A) } 10 \mu \mathrm{g}\end{array}$} & \multirow{2}{*}{$\begin{array}{l}\text { Control (1 mmol) } \\
\mathrm{AgNO}_{3}\end{array}$} & \multicolumn{3}{|c|}{ Concentration of HA AgNPs ( $20 \mathrm{mg} / \mathrm{ml}$ ), zone of inhibition (in $\mathrm{mm}$ ) } \\
\hline & & & $5 \mu \mathrm{l}(100 \mu \mathrm{g})$ & $10 \mu \mathrm{l}(200 \mu \mathrm{g})$ & $15 \mu \mathrm{l}(300 \mu \mathrm{g})$ \\
\hline Staphylococcus aureus ATCC 6538 & & - & $14 \pm 0.20$ & $15 \pm 0.15$ & $16 \pm 0.25$ \\
\hline Bacillus cereus NCIM 2106 & - & - & $14 \pm 0.25$ & $14 \pm 0.40$ & $17 \pm 0.10$ \\
\hline Pseudomonas aeruginosa ATCC 9027 & - & - & $13 \pm 0.10$ & $13 \pm 0.35$ & $18 \pm 0.15$ \\
\hline Escherichia coli ATCC 8739 & $16 \pm 0.10$ & - & $11 \pm 0.34$ & $11 \pm 0.30$ & $13 \pm 0.30$ \\
\hline
\end{tabular}

Number of experiments $=2$, mean $\pm S D$

Table 2: Determination of HA AgNp MIC against bacterial pathogens

\begin{tabular}{|c|c|c|c|c|c|}
\hline S. No. & HA AgNPs concentration $(\mu \mathrm{g})$ & S. aureus & B. cereus & P. aeruginosa & E. coli \\
\hline 1. & 100 & - & - & - & - \\
\hline 2. & 50 & - & - & - & - \\
\hline 3. & 25 & - & - & - & - \\
\hline 4. & 10 & - & - & - & - \\
\hline 5. & 5 & + & + & + & + \\
\hline 6. & 2 & + & + & + & + \\
\hline 7. & 1 & + & + & + & + \\
\hline
\end{tabular}

Number of experiments $=2$ 
The high antibacterial activity of HA AgNps may be due to the small size and large surface area of the synthesized silver nanoparticles. Till now there is no clear evidence for the action of silver nanoparticles against bacteria. It is suggested that AgNps may affect the membrane permeability of bacteria leading to disintegration of macromolecules resulting in cell death [7] or the AgNp may inactivate the proteins responsible for DNA replication and proteins responsible for adenosine triphosphate (ATP) synthesis in bacteria [21]. The biologically synthesized AgNPs using different plant extracts also showed a similar potent bactericidal activity [2].

\section{In vitro antioxidant assays}

Antioxidants are agents that restrict the deleterious effect of the oxidant reactions. These restrictions include scavenging free radicals or preventing radical formation and therefore can enhance the immune defense and lower the possibility of diseases occurrence [22]. The synthetic antioxidants have many drawbacks and hence the search of new antioxidants is of need. In the present study, the antioxidant activity of HA AgNps was investigated using three different assays to prove its efficacy as the antioxidant. The effect of various concentrations of AgNps on DPPH radical scavenging activity is shown in fig. 7.

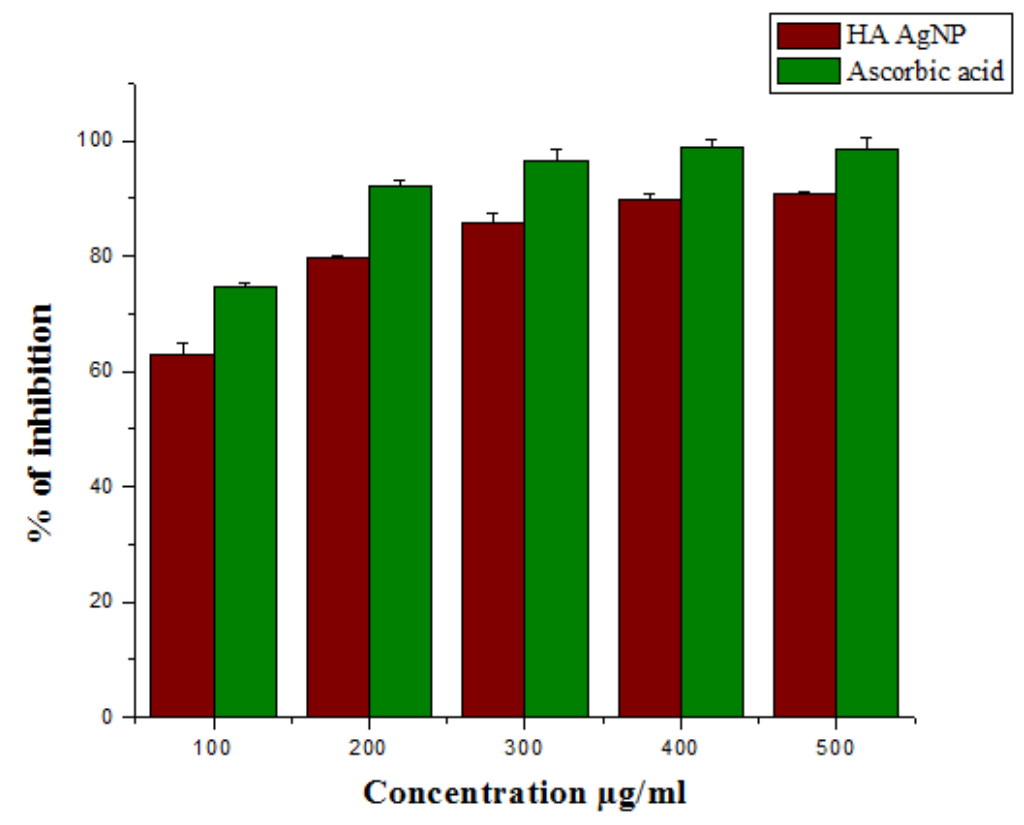

Fig. 7: DPPH radical scavenging assay of HA AgNPs when compared with the standard ascorbic acid, measurements were done in triplicates $(n=3$, mean $\pm S D)$

The free radical scavenging results show that the percentage of inhibition increases with increasing concentration of AgNps. The AgNps may donate electrons to DPPH, a lipophilic radical which readily accept electron thereby converting its color from purple to yellow that can be detected by $517 \mathrm{~nm}$. Priya et al., [23] reported the antioxidant activity of green synthesized AgNp form Pongamia pinnata extract and found significant free radical scavenging potential. The total antioxidant capacity of HA AgNPs was tested by phosphomolybednum method. This test was based on the reduction of Mo (VI) to Mo (V) that leads to the formation of a green complex. The total antioxidant potential of AgNp was shown in fig. 8.

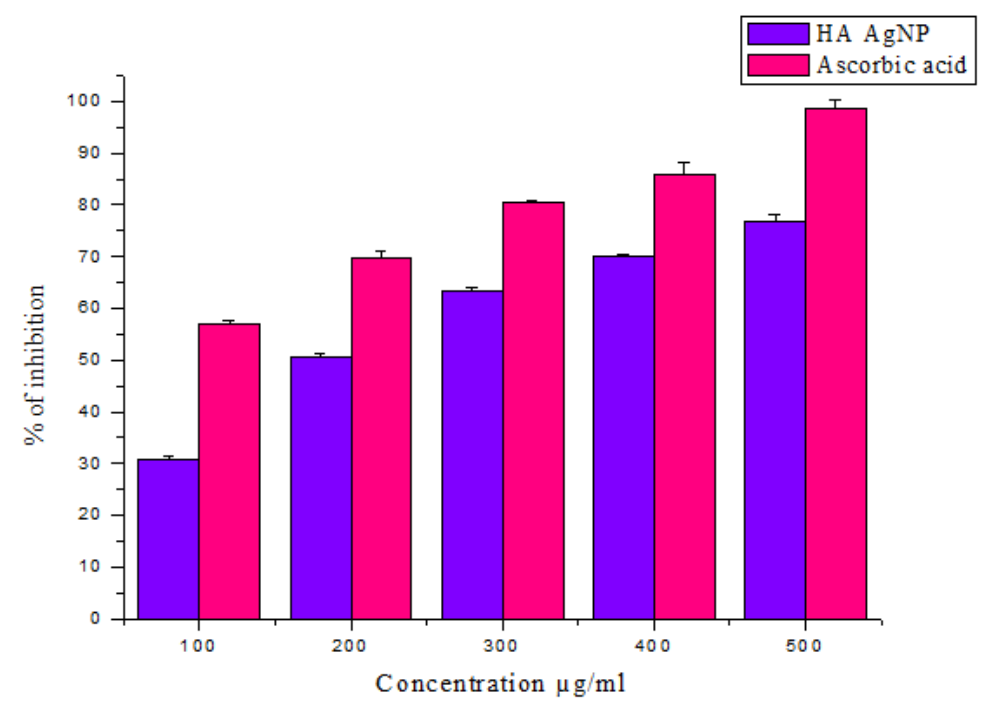

Fig. 8: Total antioxidant capacity of HA AgNPs by phospho molybdenum assay when compared with the standard ascorbic acid, measurements were done in triplicates $(n=3$, mean $\pm S D)$ 
Further, the potassium ferric cyanide reduction method may serve as a significant indicator of potential antioxidant activity. The reducing power was increased with the increasing concentration of $\mathrm{HA} \mathrm{AgNp}$ which can be depicted from the fig. 9. Similar to our study Bhakya et al,, 2016 also reported high antioxidant activity of Helicteres isora root extract. In contrast to our study Sowmya et al., 2017 [24] reported antioxidant activity of silver nanoparticles from Acalypha indica by DPPH and reducing power assay that showed more antioxidant activity as compared to standard ascorbic acid. The antioxidant activity of AgNp may be due to the bioactive compound on the surface of the AgNP.

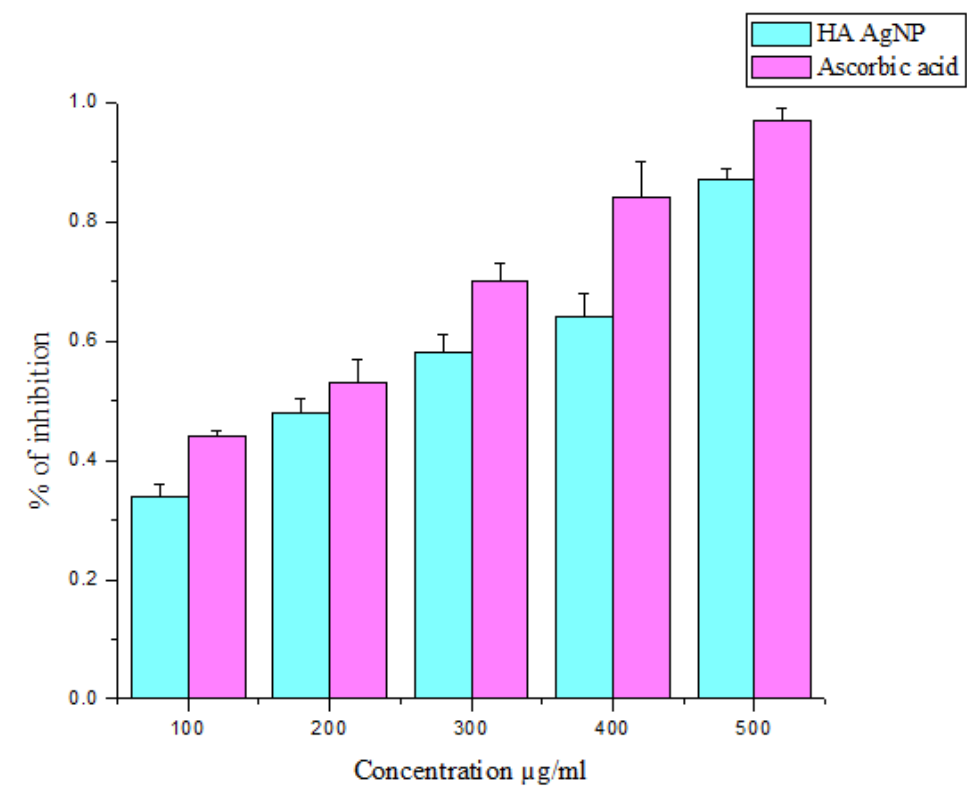

Fig. 9: Reducing power assay of HA AgNPs when compared with the standard ascorbic acid, measurements were done in triplicates (n=3, mean \pm SD)

\section{CONCLUSION}

This work provides a method for the phytosynthesis of silver nanoparticles using Hygrophila auriculata leaf extract as a reducing and capping agent without the use of any harmful reducing agents. The structural and chemical composition of the synthesized silver nanoparticles was studied using UV-vis spectroscopy, TEM, FT-IR, DLS, and XRD analysis, which proved the presence of AgNps. The biosynthesized AgNps have pronounced antibacterial activity against both gram positive and gram negative bacteria and it also has good antioxidant activity. Based on the obtained data, we suggest that the phytosynthesized AgNPs may be good alternatives in medicinal and therapeutic applications. However, proper toxicity and biocompatibility studies are to be undertaken to prove the safety and efficacy of phytosynthesized AgNps.

\section{AUTHORS CONTRIBUTIONS}

All the author have contributed equally

\section{CONFLICT OF INTERESTS}

Declared none

\section{REFERENCES}

1. Krishnaraj C, Jagan EG, Rajasekar S, Selvakumar P, Kalaichelvan PT. Synthesis of silver nanoparticles using Acalypha indica leaf extracts and its antibacterial activity water borne pathogens. Colloids Surf B Biointerfaces 2010;76:50-6.

2. Suresh G, Gunasekar PH, Kokila D, Prabhu D, Dinesh D. Green synthesis of silver nanoparticles using Delphinium denudatum root extract exhibits antibacterial and mosquito larvicidal activities. Spectrochim Acta Part A 2014;127:61-6.

3. Wan G, Ruan I, Yin Y, Yang T, Ge M. Effects of silver nanoparticles in combination with antibiotics on the resistant bacteria Acinetobacter baumanni. Int J Nanomed 2016;11:3789-800.

4. Mekkawy AI, AEl-Mokhtar M, Nafady NA, Yousef N, Hamad MA. In vitro and in vivo evaluation of biologically synthesized silver nanoparticles for topical applications: effect of surface coating and loading in to hydrogels. Int J Nanomed 2017;12:759-77.
5. Abbai R, Mathiyalagan R, Markus J, Kim Y, Wang C. Green synthesis of multifunctional silver and gold nanoparticles from the oriental herbal adaptogen: siberian ginseng. Int J Nanomed 2016;11:3131-43.

6. Gomaa EZ. Antimicrobial, antioxidant and antitumor activities of silver nanoparticles synthesized by Allium cepa extract: a green approach. J Genet Eng Biotechnol 2017;15:49-57.

7. Salehi S, Shandiz SAS, Ghanbar F, Darvish MR, Ardestani MS Phytosynthesis of silver nanoparticles using Artemisia marschalliana sprengel aerial part extract and assessment of their antioxidant, anticancer, and antibacterial properties. Int J Nanomed 2016;11:1835-46.

8. Anandalakshmi K, Venugobal J, Ramasamy V. Characterization of silver nanoparticles by green synthesis method using Pedalium murex leaf extract and their antibacterial activity. Appl Nanosci 2016;6:399-408.

9. Abdel-Aziz MS, Shaheen MS, El-Nekeety AA, Abdel-Wahhab MA. Antioxidant and antibacterial activity of silver nanoparticles biosynthesized using Chenopodium murale leaf extract. J Saudi Chem Soc 2014;18:356-63.

10. Shanmugasundaram $P$, Venkatraman $S$. Anti-nociceptive activity of Hygrophila auriculata (schum) Heine. Afr J Trad CAM 2005;2:62-9.

11. Mazumdar UK, Gupta M, Maiti S, Mukherjee D. Anti tumour activity of Hygrophila Spinosa in Ehrlich ascites carcinoma and sarcoma-180 induced mice. Indian J Exp Biol 1997;35:473-7.

12. Valientic AJ, vanhoof L, Totte J, Lasure A, Vanden Berghe, D Rwangaboo, et al. Screening of hundred Rwandese medicinal plants for antimicrobial and antiviral properties. J Ethanopharmacol 1995;46:31-47.

13. Hussain MD, Fareed S, Ali M. Hygrophila auriculata (K. Schum) Heine: Ethnobotany, phytochemistry and pharmacology. Asian J Traditional Med 2010;5:122-31

14. Kumar R, Ghoshal G, Jain A, Goyal M. Rapid green synthesis of silver nanoparticles (AgNPs) using (Prunus persica) plants extract: exploring its antimicrobial and catalytic activities. J Nanomed Nanotechnol 2017;8:4.

15. Prieto P, Pineda M, Anguilar M. Spectrophotometric quantitation of antioxidant capacity through the formation of a 
phosphomolybdenum complex: specific application to the determination of Vitamin E. Anal Biochem 1999;269:337-41.

16. Subramanian R, Subbramaniyan P, Vairamuthu Raj. Antioxidant activity of the stem bark of Shorea roxburghii and its silver reducing power. Springer Plus 2013;2:28.

17. Sunita P, Rajeshwari S, Rajiv P, Venckatesh R, Seenivasan R. Green synthesis of silver nanoparticle from leaf extract of Aegle marmelos and evaluation of its antibacterial activity. Int J Pharm Pharm Sci 2015;7:169-73.

18. Bhakya S, Muthukrishnan S, Sukumaran M, Muthukumar M Biogenic synthesis of silver nanoparticles and their antioxidant and antibacterial activity. Appl Nanosci 2016;6:755-66.

19. Vivek VA, Subhash N, Shakilabanu A, Kurian GA. Characterization and biological evaluation of silver nanoparticles synthesized by aqueous root extract of Desmodium gangeticum for its antioxidant, antimicrobial and cytotoxicity. Int J Pharm Sci 2014;7 Suppl 1:182-6.
20. Vellaichamy B, Periakaruppan P. A facile, one-pot and ecofriendly synthesis of gold/silver nanobimetallics smartened rGO for enhanced catalytic reduction of hexavalent chromium RSC Adv 2016;6:57380-8.

21. Feng QL, Wu J, Chen GQ, Cui FZ, Kim TN, et al. A mechanistic study of the antibacterial effect of silver ions on Escherichia coli and Staphylococcus aureus. J Biomed Mater Res 2000;52:662-8.

22. Wu D, Cederbaum AI. Alcohol, oxidative stress, and free radical damage. Alcohol Res Health 2003;27:277-84

23. Priya RS, Geetha D, Ramesh PS. Antioxidant activity of chemically synthesized AgNPs and biosynthesized Pongamia pinnata leaf extract mediated AgNPs-A comparative study. Ecotoxicol Environ Saf 2016;134:308-18.

24. Soumya M, Happy A, Rajesh KS, Venkat KS. Green synthesis of silver nanoparticles using medicinal plant Acalypha indica leaf extracts and its application as an antioxidant and antimicrobial agent against food borne pathogens. Int J Appl Pharm 2017;9:242-50 